\section{The academic sphere}

\author{
David E. H. Jones
}

Science of Fullerenes and Carbon Nanotubes. By M. S. Dresselhaus, G. Dresselhaus and P. C. Eklund. Academic: 1996. Pp. 965. \$130, £95.

A Himalayan expedition once set out to track down the elusive Yeti. Reporters were waiting at the base camp when the team returned. "Did you find it?" they asked excitedly. "Have you captured a Yeti?" "Well, no", replied the leader; "But

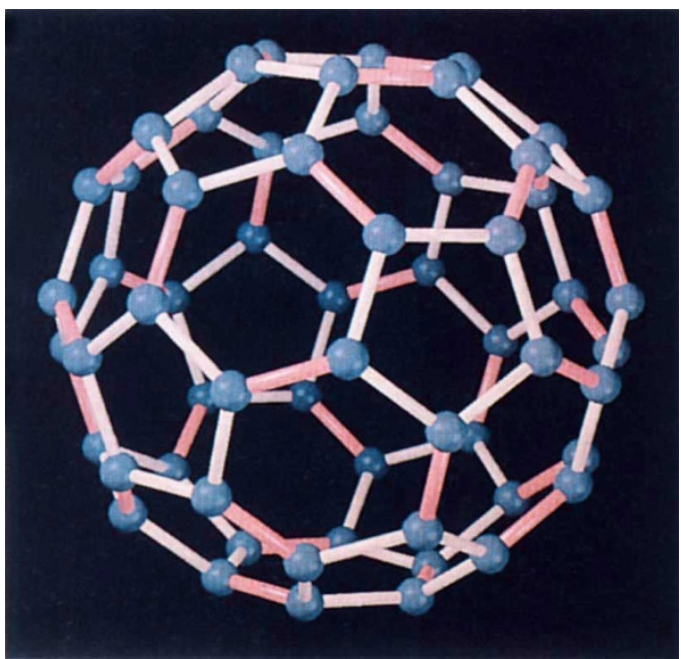

Supercomputer simulation of the atomic structure of a $\mathrm{C}_{60}$ molecule.

we do have spectroscopic evidence for its existence".

Buckminsterfullerene, the famous spherical graphite molecule, still seems haunted by its spectroscopic past. Originally identified in 1985 as a remarkably intense peak corresponding to $\mathrm{C}_{60}$ in a mass spectrum, it became available in gram quantities in 1990 by direct synthesis from graphite in a low-pressure carbon arc. And yet, in the pages of this book, it still exists largely as a trace on the screens of an ever wider suite of instrumentation, and the subject of arcane calculations seeking to explin that trace.

This approach is understandable. The novel form of the molecule, its high symmetry and intriguing bonding, pose a delightful set of tricky challenges to the theorist. Even better, the challenge extends to many related compounds the isomeric and higher fullerenes, the doped, metallated and substituted fullerenes, and carbon nanotubes. Furthermore, the resulting predictions can usually be squared quite well with the spectroscopic findings. This book claims to be the first comprehensive guide to the whole field of fullerenes, and is copiously referenced up to 1995 . It presents the physicist's part of the picture - the symmetry properties of $\mathrm{C}_{60}$ and its derivatives, their crystal structures and mass-spectral characteristics, their vibrational, electronic, transport, magnetic, optical and surface-scattering properties - in clear detail and with confidence.

By contrast, the chemist's side of the picture is sketched much more tentatively. Here is an actual chemical substance: a new allotrope of carbon, perhaps the first new allotrope of any element to have been discovered this century. What does it look like? How do you handle it? What can you do with it? Such concrete questions arise most naturally in the chapters covering the preparation of $\mathrm{C}_{60}$ and its chemical properties, and are not well answered. The topics are carefully referenced, but the text itself lacks chemical detail. It describes many new compounds with a $\mathrm{C}_{60}$ moiety in the molecule, but is content to give their proposed structures. What effect does this massive substituent have on the characteristic properties of these compounds? How stable are they? What new tricks do they get up to? Do not enquire within.

The melting point of $\mathrm{C}_{60}$ provides another example. In the table of properties, it is given as $1,180{ }^{\circ} \mathrm{C}$. A sketched phase diagram shows its triple point at about $1,800{ }^{\circ} \mathrm{C}$ and 13 bar. The caption warns that this is an extrapolation and that the existence of a liquid phase remains to be proven. Now $\mathrm{C}_{60}$ is stable at well above $2,000{ }^{\circ} \mathrm{C}$, as shown by its synthesis in a carbon arc. It ought to melt without decomposition, although its liquid range might be very narrow. So why has nobody subjected $\mathrm{C}_{60}$ to $1,800{ }^{\circ} \mathrm{C}$ and 13 bar? Again, the authors are silent, apart from providing references. A short search from these starting points turned up one paper saying how interesting it would be to melt $\mathrm{C}_{60}$, three ingenious but divergent calculations about its possible melting point, but no actual attempts to melt it. Clearly the authors are not alone in treating $\mathrm{C}_{60}$ research as largely a theoretician's playground. If the book were a novel, I'd have to say that the central character never comes alive.

This is a pity, because $\mathrm{C}_{60}$ and its relatives have caught the collective chemical imagination in a way few other molecules have done. It may well be the most intensely researched single molecule in modern chemistry. And yet its study remains oddly introverted. On the evidence of this book, fullerene research is entirely about fullerenes. It is not about the impact of fullerenes on other aspects of science or technology, because (as yet) there is almost no such impact. Even the early brave hope that $\mathrm{C}_{60}$ would turn out to be the preferred form of interstellar carbon has not been borne out. The final chapter scrapes together a few potential applications - photoresists, lubricants, photoconducting surfaces and so on but nothing to get excited about. By and large, a scientist or technologist outside the field still has no professional reason to pay any attention to it.

This seems almost incredible, and it surely cannot last. The fullerenes must have wider implications than their mere novelty. I am reminded of the curious limbo in which the newly invented laser found itself in the early 1960s. It was universally recognized as an exciting device, a splendid piece of new physics, but nobody had much idea of what it might be good for. It took at least a decade for the laser to 'grow up' and start to make its mark on physics, chemistry and technology. I remain optimistic that the fullerenes will follow the same sort of trajectory. Watch this space!

David E. H. Jones is in the Department of Chemistry, University of Newcastle upon Tyne, Newcastle upon Tyne NE1 7RU, UK.

Perfect Symmetry: The Accidental Discovery of Buckminsterfullerene by Jim Baggott is now out in paperback (Oxford University Press, £9.99). See Nature 372, 514 (1994).

\section{Climate reversal}

\section{Stephen H. Schneider}

Global Warming: The Truth Behind the Myth. By Michael L. Parsons. Plenum: 1995. Pp. 271. \$27.95.

MiChAEL Parsons claims the scientific and ethical high ground of 'truth' in this crusade against "professional environmentalists and others whose jobs depend upon the continuing environmental crises". $\mathrm{He}$ also attacks the "many scientists [who], for completely different reasons, fuel a fire of hysteria with "data-free speculation" because "career pressures have become very strong in contemporary science". "Investigating fraud in science", he says, "tells us a lot about these pressures".

Parson thus implies that it is dishonesty that has motivated 'consensus' scientists, such as those on the Intergovernmental Panel on Climate Change (IPCC), to express serious and growing concernabout global warming. He claims, for example, that "some scientists and many environmental activists warn that increases in anthropogenic greenhouse gases might cause a runaway global warming effect". But I am not aware of any scientist or environmental activist who has ever used the phrase 'runaway global warming' in the context of Earth (the jargon is usually reserved for the oven-like super-green- 